\title{
The influence of brushing on the surface quality of aluminium
}

\author{
Uwe Teicher", Richard Schulze, Alexander Brosius and Andreas Nestler \\ Technische Universität Dresden, Institute of Manufacturing Technology, 01062 Dresden, Germany
}

\begin{abstract}
The extension of technical capabilities of machine centres for complete machining of components can improve their performance. In the field of sheet metal machining, the objective beside the classic milling operation was a generation of functional surfaces by face brushing. The experimental studies have probed the influence of tools and technological parameters on the surface quality. In addition to an analysis of the relevant roughness parameters the formation of the surface topography was analysed by several measurement methods. By the application of force measurement, the results of the surface quality can be interpreted additionally. It could be shown that the feed rate in contrast to the cutting speed has the main influence on the surface roughness. A peculiarity is given by the parameter-based width of cut that should be known for reliable process control. The acquired data can be applied in the form of process characteristic fields for further processing with simulation and modelling methods.
\end{abstract}

\section{Introduction}

Technical surfaces are becoming increasingly sophisticated due to increasing demands. This development leads to so-called engineered surfaces, to which a function is assigned in addition to the actual form [1].

In the field of mechanical engineering, the tribological properties of the surfaces are in the foreground. This includes, for example, the specific structuring of functional surfaces for the preparation of subsequent processes in the form of joining by adhesion [2]. But also improvements in hardness and fatigue strength can be achieved by specific machining $[3,4]$.

The methods to achieve this structuring are manifold. These include grinding and blasting techniques [5]. However, the application of hybrid techniques in the form of vibration superimposed milling shows that repeatable surface structures can be produced in a controlled manner [6].

The process brushing, which has not yet been the focus of scientific research, has a potential to generate excellent results regarding productivity and flexibility. Research was focused on analyses of the filament stiffness [7], the filament bending in contact [8] and the resulting forces [9]. But these aspects are interrelated and this could be shown in sophisticated models [10].

\footnotetext{
*Corresponding author: uwe.teicher@tu-dresden.de
} 
With regard to the surface quality, on the one hand, comparable relationships can be determined as in the grinding process. This includes, for example, the dependence of roughness parameters from the used grit size [10]. On the other hand, the special features of brushing due to the flexible filaments are identified by analysing the chip formation processes [4,11] and the application of areal based parameters according to ISO 25178 [12].

A decisive factor for the applicability of a process is its flexibility, feasibility and costbenefit ratio. Methods with geometrically indeterminate cutting edges are often superior to hybrid processing methods due to superimposed vibrations in terms of the necessary technical requirements. However, it should also be illustrated to which extent the technical application of brushing on milling machining centres are possible in order to integrate several machining processes in one single clamping situation.

The evaluation is based on an analysis of the surface quality after face brushing with roughness parameters and the characterization of the process with its special characteristic features.

\section{Experimental conditions}

The experimental machining tests were carried out on a high speed machining centre Mikromat 4V HSC (Dresden, Germany) (Figure 1).

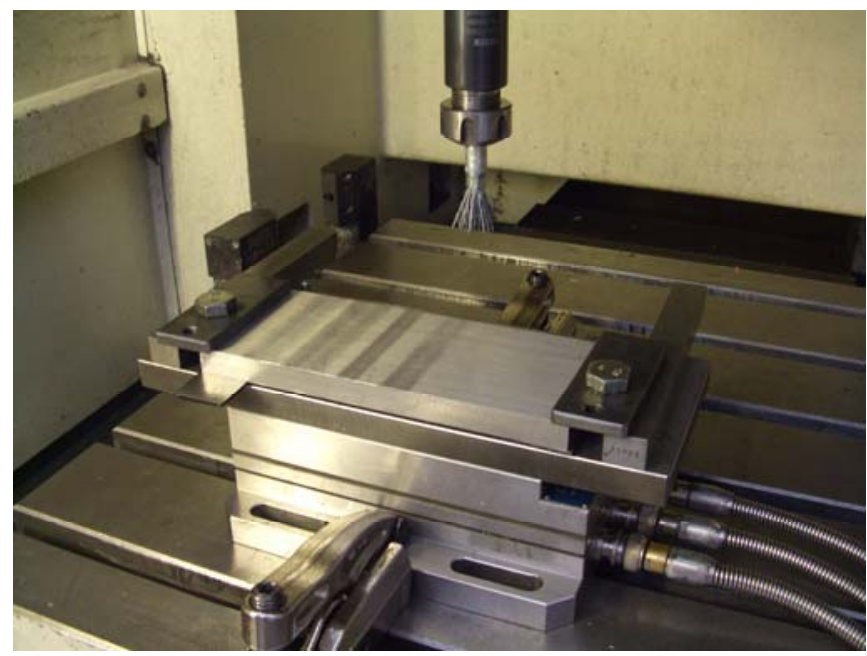

Fig. 1. Set-up for the brushing experiments.

The test sheets were connected with force closure on a dynamometer type 9257A from Kistler (Kistler Instrumente AG, Winterthur, Switzerland) and the machine table. The signals from the dynamometer were digitized with the aid of the charge amplifier 5007 from Kistler and the measuring card (DAQ) USB Basic from Goldammer GmbH Soft- \& Hardware Entwicklung (Wolfsburg, Germany) and recorded and evaluated with the software National Instruments DIAdem 8.1 (Austin, USA).

The brushing tools of type Alpha from the company Kullen-KOTI GmbH (Reutlingen, Germany) were clamped with the help of a collet chuck with a shaft diameter of $6 \mathrm{~mm}$ and used for face machining. These brushes are characterized by being designed as heat stabilized polyamide bristles enriched with $20-40 \%$ of abrasive bristles. Further details of the brush used can be found in Table 1 . The roughness was measured $\left(\lambda_{c}=0.8 \mathrm{~mm}, l t=4.8\right.$ $\mathrm{mm}$ ) and evaluated with the aid of the T8000 roughness and contour measuring system from Hommel-Etamic (Villingen-Schwenningen, Germany). 
Table 1. Characterization of the brush.

\begin{tabular}{|l|l|}
\hline \multicolumn{1}{|c|}{ Visualisation } & \multicolumn{1}{c|}{ Description } \\
\hline & $\begin{array}{l}\text { Nominal diameter of the brush: } 12 \mathrm{~mm} \\
\text { Diameter of one bristle: } 1 \mathrm{~mm} \\
\text { Abrasive: SiC } \\
\text { Grit size: FEPA } 120(115 \mu \mathrm{m})\end{array}$ \\
\hline
\end{tabular}

Variation parameters in the experimental investigations were technological in the form of cutting speed, feed rate and axial infeed, i.e. depth of cut. The aluminium alloy EN-AW5754 (AlMg3), which is widely used in apparatus, metal and vehicle construction, was used as the material for the experiments.

\section{Results and discussion}

Before the machining process was started, the surface parameters of roughness $R z$ and $R a$ were determined by tactile measurements to determine the influence of the machining process on brush machining. Despite the potential contamination of polymeric particles, which can remain on the material due to the process heat and thus influence the surface topography and the surface parameters derived from it, the use of a cooling lubricant was not used in order to obtain precise information on the acting cutting force components. At least with the help of a microscopic analysis, no residual particles could be observed on the surface.

A special point when using brushing tools is the fact that they are elastic in nature. Therefore, process forces and geometrical preferences have an effect on the bending of the bristle and therefore on the process design. This fact is also the subject of current research work [13]. Figure 2 illustrates this situation, in that the relationship between the set cutting depth and the measurable real width of cut is shown, starting from the nominal brush diameter of $12 \mathrm{~mm}$. Due to the elastic properties of the bristle, they are pushed away as the axial infeed increases and thus increase the effective real width of cut leading to a characteristic contact zone geometry [14]. The real width of cut $a_{e r}$ can double compared to the nominal one and accordingly the diameter of the brush. A solution to prevent the spreading of the bristles can be the application of elastic bands [12].

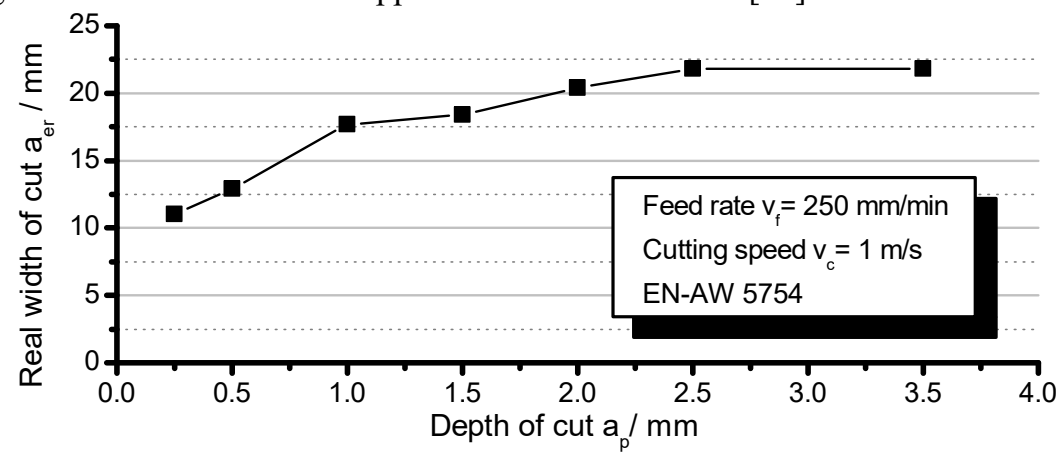

Fig. 2. Real width of cut during brushing as a function of the depth of cut.

A decisive point during brushing is the fact that, due to the tool geometry, a nonspecified number of elements of the surface to be processed only comes in contact with the bristles when passing over surface with the brushing tool. This is depended of the tool 
configuration and the technological parameters and can lead from a contact of only single bristles with the surface to a complete interaction of the brush passing the surface. For this reason, when performing the brushing experiments, it is necessary to indicate the corresponding parameters in relation to the unprocessed state. When analysing the influence of the depth of cut on the surface parameters $R a$ and $R z$, it can be seen that within the examined parameter field there are no dependencies from the set cutting depths (Figure 3 ). In principle, however, a minimum cutting depth is necessary in order to establish reliable contact with the material surface with the bristles. The reasons for this are, on the one hand, production-related deviations in bristle length and, on the other hand, differences in the wear pattern. With the set of parameters defined in Figure 3, it can be observed that a reduction of the measured roughness parameters in relation to the respective initial state prior to processing $\left(R z_{b}, R a_{b}\right)$ can be obtained by brushing.

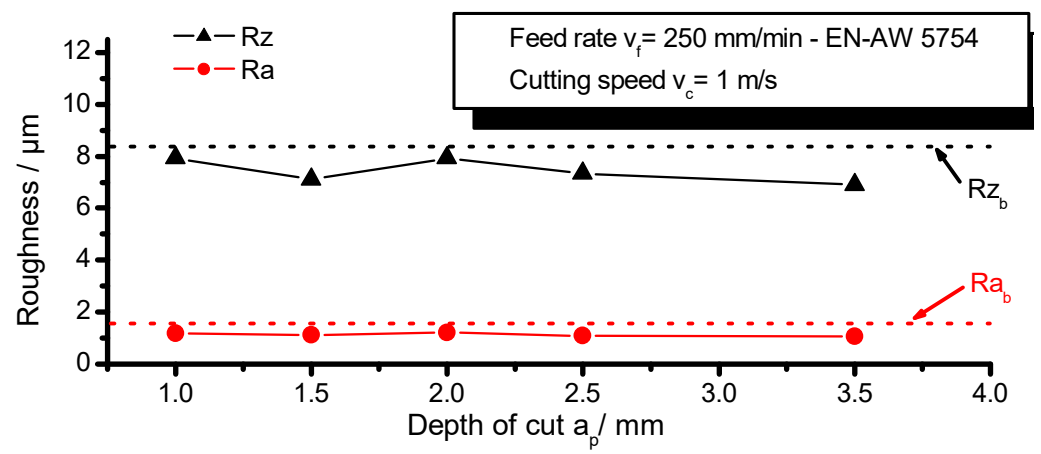

Fig. 3. Influence of the depth of cut on the roughness parameters.

A clear influence of the feed rate on the roughness values can be shown. (Figure 4).

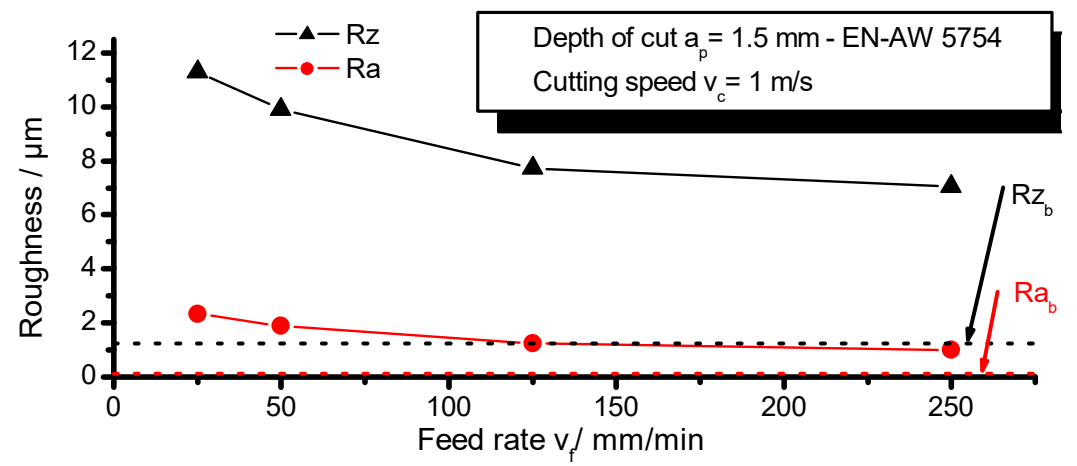

Fig. 4. Influence of the feed rate on the roughness parameters.

However, it is important that the correlation shown in Figure 4 cannot be generalized, that the roughness characteristic values decrease with increasing feed rate. Rather, the roughness values from machining asymptotically approximate the roughness values with increasing feed rate, as only individual bristles interact with the workpiece surface at extremely high feed rates. In the case for different boundary conditions it can be shown that there is no significant relation between the feed rate and the surface quality [12]. This fact becomes valid if the cutting speed is kept constant. With regard to the relationship between the roughness parameters and the cutting speed, it can be observed that there is a tendency towards lower or process-specific values with increasing cutting speed (Figure 5). This means that with increasing cutting speed with constant boundary conditions (feed rate etc.) it can be assumed that all surface elements crossed by the tool come into contact with the 
bristles. This is particularly the case for the position of the tool axis in Figure 6 at the abscissa of $9 \mathrm{~mm}$. However, another effect is given at increasing cutting speed with a declining effective real width of cut, because the bristles are deflected due to the centrifugal force.

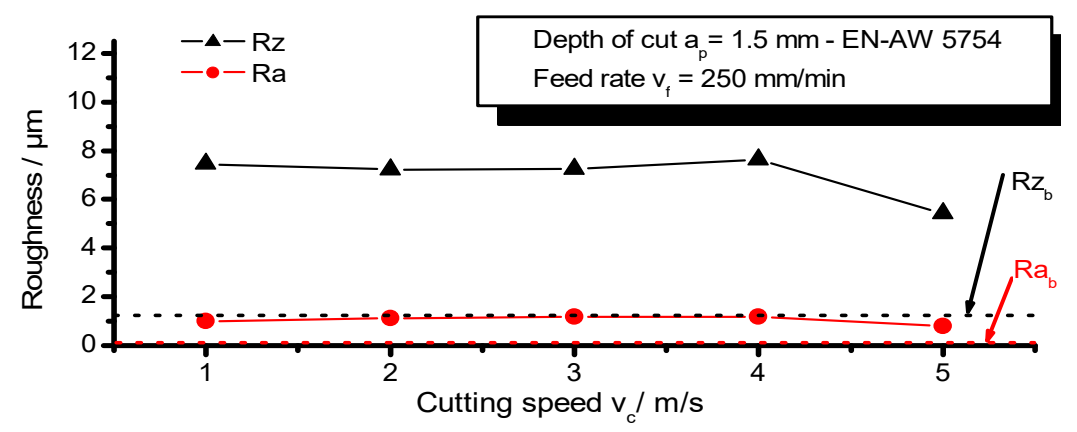

Fig. 5. Influence of the cutting speed on the roughness parameters.

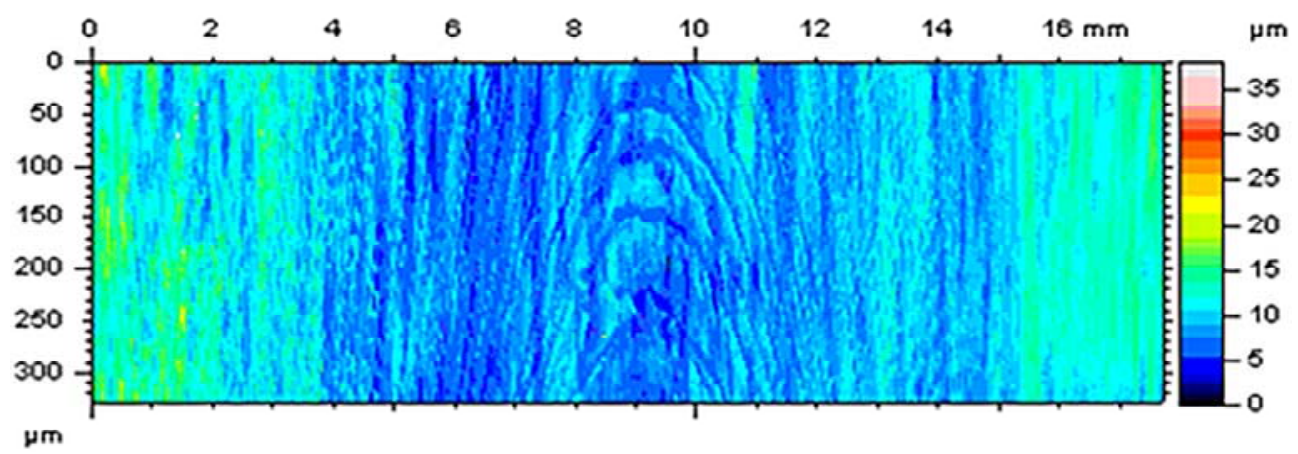

Fig. 6. 3D surface topography of a brushed aluminium sheet $\left(a_{p}=1 \mathrm{~mm}, v_{c}=1 \mathrm{~m} / \mathrm{s}, v_{f}=250 \mathrm{~mm} / \mathrm{min}\right.$; ordinate direction $=$ feed direction).

As expected, the forces during machining are very low. In the case of face brushing, it is difficult to determine the cutting portion of the resultant force during machining, so that the feed portion was used for evaluation. At least, the curve of the thrust force as a function of the feed rate shows an expected behaviour in which the thrust force increases with higher feed rates (Figure 7). With regard to the thrust force as a function of the cutting depth, it can be shown that there is a sudden increase in the thrust force as the cutting depth increases. The reason for this is to be found in the effective speed-dependent length of the individual bristles, so that if a minimum cutting depth is exceeded, a majority of the bristles are engaged.

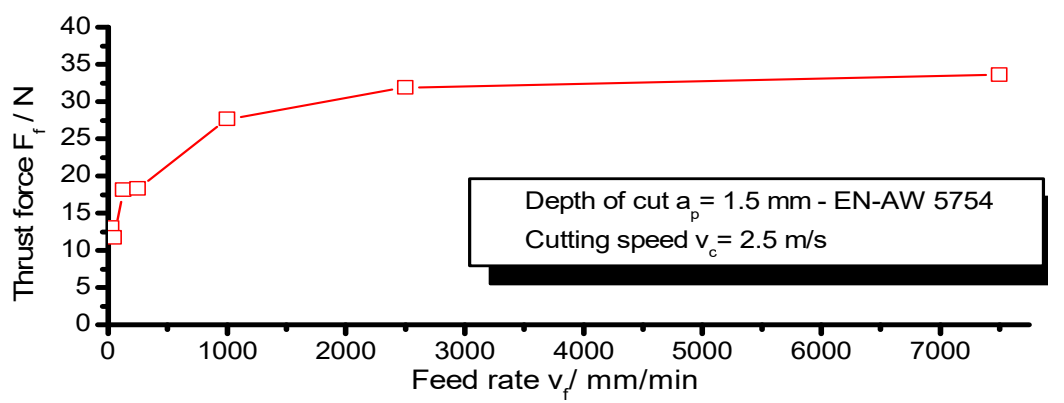

Fig. 7. Influence of the feed rate on the thrust force during brushing. 


\section{Summary and conclusions}

Brushing is certainly one of the promising technologies in the field of machining, which opens up fundamentally new process and application fields. A prerequisite for this is a basic understanding of the process that has to be worked out.

This includes, among other things, the consideration of the elastic behaviour of the bristles and the process-specific peculiarity of the real width of cut depending on adjusted technological values.

But also the facts of the technology-dependent correlation between the number of bristles that come into contact with the surface of the workpiece and the crossed surface must be taken into account for an effective process design.

For this reason, it is not necessarily possible to derive correlations between the set technology parameters and measured surface parameters.

A significant influence on the roughness is given by the setting of the feed rate, with which, however, a roughening as well as smoothing character can be realized.

For the parameters of the cutting speed and the depth of cut a characteristic value changing character can be proven, although the variation of the respective parameters have only a small influence or not consistently proven tendencies on the roughness.

The authors would like to thank Federal Ministry for Economic Affairs and Energy (BMWi), as well as AiF Projekt $\mathrm{GmbH}$ and $\mathrm{MB}$-Portatec $\mathrm{GmbH}$ for their support during the project und Kullen-KOTI for the brushes.

\section{References}

1. K. J. Stout, KSME Int. J. 14, 72 (2000)

2. C. W. Jennings, J. Adhes. 4, 25 (1972)

3. J. Lobos, S. Suzuki, H. Nakajima, Y. S. Ji, H. Fujii, D. Terada, N. Tsuji, J. Phys. Conf. Ser. 165, 12070 (2009)

4. R. W. Overholser, R. J. Stango, R. A. Fournelle, Int. J. Mach. Tools Manuf. 43, 193 (2003)

5. A. F. Harris A. Beevers, J. Adhes. 19, 445 (1999)

6. D. Biermann, T. Surmann, S. Odendahl, T. Brüggemann, E. Krebs, Proc. 2nd Int. Conf. Process Mach. Interact. (2010)

7. R. J. Stango, S. M. Heinrich, C. Y. Shia, J. Eng. Ind. 111, 238 (1989)

8. S. M. Heinrich, R. J. Stango, C. Y. Shia, J. Eng. Ind. 113, (1991)

9. R. J. Stango, V. Cariapa, A. Prasad, S.-K. Liang, J. Eng. Ind. 113, 283 (1991)

10. E. Uhlmann, C. Sommerfeld, M. Renner, M. Baumann, Wt Werkstattstech. 107, 472 (2017)

11. R. J. Stango, R. A. Fournelle, S. Chada, J. Eng. Ind. 117, 9 (1995)

12. N. Raymond, S. Hill, M. Soshi, Int. J. Adv. Manuf. Technol. 86, 2069 (2016)

13. F. Novotný, M. Horák, M. Starý, Int. J. Mach. Tools Manuf. 118-119, 61 (2017)

14. V. Cariapa, R. J. Stango, S.-K. Liang, A. Prasad, J. Eng. Ind. 113, 290 (1991) 